This item was submitted to Loughborough's Research Repository by the author.

Items in Figshare are protected by copyright, with all rights reserved, unless otherwise indicated.

\title{
Implicit STEM ability beliefs predict secondary school students' STEM self- efficacy beliefs and their intention to opt for a STEM field career
}

\section{PLEASE CITE THE PUBLISHED VERSION}

https://doi.org/10.1002/tea.21506

\section{PUBLISHER}

(c) Wiley

\section{VERSION}

AM (Accepted Manuscript)

\section{PUBLISHER STATEMENT}

This is the peer reviewed version of the following article: VAN AALDEREN-SMEETS, S.I., WALMA VAN DER MOLEN, J.H. and XENIDOU-DERVOU, I., 2018. Implicit STEM ability beliefs predict secondary school students' STEM self-efficacy beliefs and their intention to opt for a STEM field career. Journal of Research in Science Teaching, 56 (4), pp.465-485, which has been published in final form at https://doi.org/10.1002/tea.21506. This article may be used for non-commercial purposes in accordance with Wiley Terms and Conditions for Use of Self-Archived Versions.

\section{LICENCE}

CC BY-NC-ND 4.0

\section{REPOSITORY RECORD}

van Aalderen-Smeets, Sandra I., Juliette H. Walma van der Molen, and Iro Xenidou-Dervou. 2019. "Implicit STEM Ability Beliefs Predict Secondary School Students' STEM Self-efficacy Beliefs and Their Intention to Opt for a STEM Field Career". figshare. https://hdl.handle.net/2134/33428. 


\section{Implicit STEM ability beliefs predict secondary school students' STEM self-efficacy beliefs and their intention to opt for a STEM field career}

\begin{tabular}{|r|l|}
\hline Journal: & Journal of Research Science in Teaching \\
\hline Manuscript ID & JRST-2017-11-0451.R2 \\
\hline Wiley - Manuscript type: & Research Article \\
\hline Conceptual Area: & Learning \\
\hline Methodology: & Quantitative (includes experimental, quasi-experimental, large scale) \\
\hline Grade Level: & Secondary (age 14-18) \\
\hline Science Content Area: & General Science \\
\hline Research Focus/Suggested & teacher/student empowerment, student beliefs, values, stress/coping, \\
Keywords: & pedagogy, attitudes and achievement \\
\hline & \\
\hline
\end{tabular}

SCHOLARONE ${ }^{\mathrm{m}}$

Manuscripts 


\title{
Implicit STEM ability beliefs predict secondary school students' STEM self-efficacy beliefs and their intention to opt for a STEM field career.
}

\author{
Sandra I. van Aalderen-Smeets ${ }^{1,2}$, Juliette H. Walma van der Molen ${ }^{2}$, and Iro \\ Xenidou-Dervou ${ }^{3}$
}

\begin{abstract}
${ }^{1}$ Academy of Pedagogy and Education, Saxion University of Applied Sciences, Deventer, the Netherlands. ${ }^{2}$ Center for Science Education and Talent Development, Faculty of Behavioral, Management, and Social Sciences, University of Twente, Enschede, The Netherlands. ${ }^{3}$ Mathematics Education Centre, Loughborough University, Loughborough, UK.
\end{abstract}

Correspondence:

Dr. Sandra van Aalderen-Smeets

Saxion University of Applied Sciences

PO box 70.000

$7500 \mathrm{~KB}$ Enschede

The Netherlands

s.i.vanaalderen@saxion.nl

This research was funded by TechYourFuture, the Dutch center of expertise in technology education, project 13 . 


\begin{abstract}
Despite the widely-accepted view that low self-efficacy beliefs negatively influence students' intention to opt for a STEM field oriented study or career path, it remains unclear how to effectively stimulate these beliefs in students who do seem to have the ability and motivation to opt for a STEM career. A suggestion from previous literature is that students' implicit beliefs about the malleability of their learning ability can have a major impact on their self-efficacy beliefs, and, importantly, that these implicit beliefs are malleable themselves. Even though this relation between implicit beliefs, self-efficacy, and STEM field aspirations has been suggested multiple times, there is no empirical evidence to support this claim. The goal of the current study was to examine whether implicit beliefs about the malleability of STEM ability are associated with secondary school students' intention to opt for a STEM field bachelor's degree, using a Structural Equation Modelling approach. Furthermore, we examined the mediating role of STEM-oriented self-efficacy beliefs on the relationship between implicit ability beliefs and STEM intention. We used a Likert-type questionnaire, consisting of subscales to measure ability beliefs, self-efficacy, and intention to opt for a STEM degree of secondary school students in their fifth grade $(n=483)$. Results showed that there is a positive relation between implicit STEM ability beliefs and the intention to opt for a STEM field bachelor degree, and that this relation is partly mediated by self-efficacy beliefs. Incremental STEM ability beliefs predicted positive self-efficacy beliefs and increased STEM intention. These findings provide a foundation for a novel approach to stimulate and motivate students for the STEM field, namely by stimulating incremental beliefs about their STEM ability.
\end{abstract}

Keywords: [teacher/student empowerment, student ability beliefs, self-efficacy, stress/coping, pedagogy, STEM education] 
Implicit beliefs and STEM choice

\section{Implicit STEM ability beliefs predict secondary school students' STEM self- efficacy beliefs and their intention to opt for a STEM field career.}

Western knowledge-based societies are highly dependent on a strong technological and innovative workforce. The sufficient inflow of students into science, technology, engineering, and mathematics (STEM) education is, therefore, essential to guarantee a strong position in the global economy. However, secondary school students' lack of interest to opt for a STEM field career is continuing to be an area of concern (Bøe, Henriksen, Lyons, \& Schreiner, 2011; DeWitt \& Archer, 2015; OECD, 2017; Regan \& DeWitt, 2015; U.S. Congress Joint Economic Committee, 2012). Although previous research identified a multitude of factors that constitute STEM motivation (Glynn, Brickman, Armstrong, \& Taasoobshirazi, 2011) and a multitude of factors that may influence students' motivation for STEM career paths (van Tuijl \& Walma van der Molen, 2016; Wang \& Degol, 2013), it remains a challenge to positively stimulate students' STEM interest, especially where girls are concerned. In this paper we investigate an alternative factor that might predict students' intention to opt for a STEM field study path, namely the role that implicit ability beliefs may play in students' intention to opt for STEM.

The contribution of implicit ability beliefs to STEM interest and motivation has been suggested before (Dweck, 2006, 2008), but the mechanism underlying the relationship between ability beliefs and STEM educational choices has never been empirically investigated. If this relation can be supported by evidence, it may stimulate new approaches to enhance students' STEM motivation by stimulating more positive implicit ability beliefs. This paper presents an empirical study of the relationship between implicit ability beliefs and secondary school students' intention 
to opt for a STEM field study path and thereby aims to provide more insight into the psychological processes underlying students' STEM field choices.

Students' lack of interest in the STEM field becomes most notable at the end of primary school and during secondary school (Osborne \& Dillon, 2008, DeWitt \& Archer, 2015; Van Tuijl \& Walma van der Molen, 2016). One salient factor that has been repeatedly designated as contributing to secondary school students' reluctance to opt for a STEM-oriented study path is students' low self-efficacy beliefs regarding STEM subjects (Betz \& Hackett, 1983; Borgen \& Betz, 2008; O’Brien, MartinezPons, \& Kopala, 1999; Wigfield \& Eccles, 2000). Self-efficacy beliefs refer to the perceived ability of an individual to perform a particular behavior that may contain difficult and stressful elements (Bandura, 1997), for example whether students believe they will do well in school-subjects such as mathematics, chemistry, or physics.

Self-efficacy has been shown to be directly related to students' college science grade averages (Glynn et al., 2011). However, stimulating positive self-efficacy beliefs is not self-evident. A review of interventions targeting motivation for STEM showed that half of the interventions targeting self-efficacy were unsuccessful (Rosenzweig \& Wigfield, 2016). New approaches to stimulate self-efficacy beliefs thus seem necessary. Bandura (1977) stated that self-efficacy beliefs are derived from the cognitive appraisal of four categories of experiences: enactive mastery, vicarious experience, verbal persuasion, and physiological arousal. How this appraisal comes about or on which factors this is dependent on is less clear.

Research on motivation has shown that self-efficacy beliefs themselves may be preceded or influenced by students' implicit beliefs about the malleability of their learning abilities (in previous work also called implicit beliefs about intelligence or growth/static mindset) (Dweck, 2000). According to Carol Dweck's (2000) 
Implicit beliefs and STEM choice

motivational model of achievement, some students believe their abilities are a fixed or unchangeable entity (entity beliefs), while others believe that their abilities are a quality that can be changed and developed through experience and practice (incremental beliefs), although they do recognize the influence of aptitude. Dweck's motivational model claims that these implicit ability beliefs determine how students approach learning, how they deal with setback experiences, how vulnerable they are to decreases in self-efficacy beliefs, how sensitive they are to stereotypical beliefs, their persistence and grit, and eventually their achievement (e.g., Aronson, Fried, \& Good, 2002; Burnette, O’Boyle, Claro, Paunesku, \& Dweck, 2016; Dweck, 2000; VanEpps, Pollack, \& Finkel, 2013). Although a relation between implicit ability beliefs and achievement has often been suggested, this is still a topic of debate. One recent study by Bahník \& Vranka (2017) failed to find evidence for it, while another recent study did find evidence to support this claim (Susperreguy, Davis-Kean, Duckworth \& Chen, 2017).

Nevertheless, these implicit ability beliefs may complement Bandura's selfefficacy theory. As Bandura (2006) states, it is not so much the experience itself, but rather the interpretation or appraisal of the experience that determines its influence on self-efficacy beliefs. And that is where implicit ability beliefs may exert their influence: We hypothesize that students' implicit beliefs about the malleability of their STEM abilities may influence their interpretation or appraisal of experiences such as setbacks, failure, or success, and thereby influence their self-efficacy beliefs.

The either direct or indirect contribution of implicit ability beliefs to the intention to opt for a STEM-oriented education or career (called STEM intention) has been suggested by other studies as well (Blackwell, et al., 2007; Burkley, Parker, Stermer, \& Burkley, 2010; Dweck, 2006, 2008; Murphy \& Thomas, 2008; Nix, 
Perez-Felkner, \& Thomas, 2015; Wang \& Degol, 2013; van Aalderen-Smeets \& Walma van der Molen, 2016). In addition, there is a range of research that has indicated the importance of students' achievement goal orientations, both in general education and in mathematics education (e.g. Fadlelmula, 2010; Midgley, 2002). However, so far, there has been no empirical evidence to support the claim that implicit ability beliefs may predict STEM oriented study paths. A theoretical study by van Aalderen-Smeets and Walma van der Molen (2016) hypothesized that the association between implicit ability beliefs and STEM intention is mediated by several factors, one of which is self-efficacy. The authors proposed that students who hold entity beliefs (who believe that their abilities are not malleable) are at risk for decreases in self-efficacy beliefs (Erdley, Cain, Loomis, Dumas-Hines, \& Dweck, 1997; Henderson \& Dweck, 1990; Hong, Chiu, Dweck, Lin, \& Wan, 1999; Niiya, Crocker, \& Bartmess, 2004; Robin \& Pals, 2002). When these students experience a setback or failure, they are likely to attribute this to a lack of an innate ability. On the other hand, students who hold incremental beliefs are more likely to attribute a setback to lack of effort, and thereby preserve their self-efficacy beliefs. It has been shown that over four years of college, students' self-efficacy beliefs are more likely to decline if they have an entity orientation, compared to students who hold incremental beliefs (Robin \& Pals, 2002).

Research on STEM aspirations shows that self-efficacy beliefs, in turn, may negatively affect students' STEM field aspirations, as stated above (Betz \& Hackett, 1983; Borgen \& Betz, 2008; O’Brien, Martinez-Pons, \& Kopala, 1999; Wigfield \& Eccles, 2000). This suggests that secondary school students who have stronger entity beliefs may have developed more negative self-efficacy beliefs due to setback experiences during their years in high school and may therefore be more reluctant to 
Implicit beliefs and STEM choice

opt for a STEM field oriented bachelor degree when entering college (assuming that a STEM field bachelor is appropriate for them).

Although it is unknown what determines a child's original implicit ability beliefs (nature, nurture, or most likely both), several studies have shown that these implicit ability beliefs can be changed through interventions (e.g., Blackwell, Trzesniewski, \& Dweck, 2007; Burke \& Williams, 2012; Paunesku, Walton, Romero, Smith, Yeager, \& Dweck, 2015; Schroder, Moran, Donnellan, \& Moser, 2014). This malleability of implicit ability beliefs themselves and the consequent potential effect on self-efficacy and STEM study path intentions makes this approach highly relevant for interventions aiming to stimulate STEM intentions in high school students. It suggests that a focus on stimulating incremental beliefs in high school might be a valuable complementary approach to stimulating STEM-related self-efficacy beliefs in students and thereby may increase the likelihood of students opting for a STEM career.

In the current study, we empirically investigated the suggested relationship between secondary school students' implicit beliefs about STEM ability, their STEM self-efficacy beliefs, and their intention to opt for a STEM oriented bachelor's degree. We used a Structural Equation Modelling (SEM) approach to investigate the following research questions: 1) Is there a relation between implicit STEM ability beliefs and STEM intention, and 2) If there is a direct relation between implicit STEM ability beliefs and STEM intention, is this relation (completely or partially) mediated by self-efficacy beliefs? Since the construct of implicit beliefs regarding STEM ability is new, we first inspected the validity and dimensionality of this construct. 
Implicit beliefs and STEM choice

\section{Implicit STEM ability beliefs}

Dweck's motivational theory refers to beliefs about the malleability of one's abilities in general. In the current study, we used the domain-specific measure of implicit STEM ability beliefs, since in our view such a measure is more closely related to STEM field self-efficacy beliefs and STEM aspirations. To our knowledge, thus far no studies specifically focused on students' implicit beliefs about the STEM domain in general. Several previous studies have focused on domain-specific implicit beliefs, such as those that examine implicit beliefs about the malleability of musical abilities or sports (Mascret, Falconetti, \& Cury, 2016; Smith, 2005), and those that focus on implicit beliefs about mathematics ability specifically (Rattan, Good, \& Dweck, 2012; Susperreguy et al., 2017). There are some studies that investigated the implicit beliefs of STEM teachers (Jonsson, Beach, Korp, \& Erlandson, 2012; Patterson, Kravchenko, Chen-Bouck, \& Kelley, 2016). These studies investigated STEM teachers' beliefs about learning abilities in general and compared those to the beliefs of teachers in other fields but did not actually measure a domain-specific STEM belief.

Apart from the focus on implicit beliefs about ability in general, Dweck's motivational theory has been critiqued for the use of the term 'intelligence', in both the construct itself and in the instruments that measure people's belief in the malleability of their 'intelligence'. We agree that the term 'intelligence' is complex and ambiguous and we suspect that the secondary school students in our study would vary in their interpretation of the word since it is such a complex construct. Therefore, we used the term ability and focused on students' domain-specific STEM ability beliefs.

Since the construct of implicit STEM ability beliefs was not measured before, we first established whether our measurement instrument showed adequate 
Implicit beliefs and STEM choice

convergent and discriminant validity. To assess the discriminant validity of the STEM ability beliefs subscale compared to the general ability beliefs subscale, we included a subscale measuring implicit beliefs about general abilities. In the methods section we therefore also describe a subscale measuring 'General implicit ability beliefs', but the data from this scale are not used to answer our research questions.

\section{The dimensionality of implicit ability beliefs}

Most studies on implicit beliefs assume Dwecks' construct of entity and incremental beliefs to be a single, one-dimensional construct in which one pole represents a pure entity theory (abilities are fixed), while the other pole represents an incremental theory (abilities are malleable) (e.g., Blackwell et al., 2007). However, the dimensionality of the construct has been questioned and a multidimensional construct has been suggested instead, in which implicit beliefs are represented as two separate constructs, one representing entity beliefs and the other representing incremental beliefs (see for an overview Tempelaar, Rienties, Giesbers, \& Gijselaers, 2015). For example, Tempelaar et al. (2015) and De Castella and Byrne (2015) showed that a multidimensional model of implicit beliefs fit their data better than a one-dimensional model. Most studies using a multidimensional construct do so because of the low observed correlation between the incremental and entity subscales (between .19 and .74) (e.g., Dupeyrat \& Marine, 2005; Hong et al., 1999; Tempelaar et al., 2015). These relatively low correlations are in those cases interpreted as support for the multidimensionality of the construct (but without specifying a cut-off score when a correlation would be high enough to support a one-dimensional construct). Still, most studies use implicit beliefs as a one-dimensional construct. In short, there is no clear consensus in the literature whether to regard implicit theories as a multidimensional or one-dimensional construct. We therefore examined the 
dimensionality of the construct in our present dataset, before investigating our aforementioned research questions.

\section{The current study: Building a STEM intention model for the relationship between implicit STEM ability beliefs and students' STEM intentions.}

In this paper, we gradually built a STEM intention model describing the influence of implicit beliefs on students' intention to opt for a STEM field bachelor's degree. We first established the construct validity of implicit STEM ability beliefs. Furthermore, we examined whether the construct of implicit STEM ability beliefs should be regarded as a one-dimensional construct or as a multidimensional construct (entity and incremental). Subsequently, we used the best fitting model to investigate: 1) Whether students' implicit beliefs about their STEM ability are related to their intention to choose a STEM bachelors' degree after secondary school, and 2) Whether this relationship is partly or completely mediated by STEM self-efficacy beliefs.

To investigate possible confounds that may influence the relation between implicit beliefs, self-efficacy, and STEM intention, we included achievement in STEM school subjects as a control variable in the model. Watt et al., (2006) argue that adequate achievement can be viewed as a necessary, but not a sufficient condition for making an educational and career choice and that it is important to take achievement measures into account as a control measure. Students' achievement on the STEM oriented school subjects in high school could explain a potential positive relation between self-efficacy and STEM intention (Rask, 2010; van Aalderen-Smeets \& Walma van der Molen, 2016; Wang, 2012). High self-efficacy beliefs have been shown to correlate with higher school grades in general and STEM-related areas in particular, which in turn may influence STEM educational and career choices (e.g., Glynn et al., 2011; Watt, Eccles, \& Durik, 2006; Wigfield \& Eccles, 2000). 
Implicit beliefs and STEM choice

\section{Methods}

\section{Participants and procedure}

The participants in the current study were 483 secondary school students from 11 schools ( $46.2 \%$ boys, mean age $16.5, S D=.67$, range 14 to 19 years) across different regions in The Netherlands. All participants were in their fifth grade of secondary school and were enrolled in the preparatory university level of the Dutch secondary school system (in Dutch: VWO). There are three levels in the Dutch secondary-school system, of which the preparatory university level is the most demanding level, preparing students for a bachelor's degree at university. About $20 \%$ of secondary school students are eligible to follow this track. The students were in their fifth year and orienting towards choosing a bachelor's degree, but still had a year ( $6^{\text {th }}$ grade) before a decision had to be made. Unlike the broad-oriented bachelor's degrees in, for example, the United States, bachelor-degree studies in The Netherlands are traditionally more narrow or even subject-specific, focussing on one particular subject (e.g., Mathematics or Biology degree). Most STEM-oriented degrees at university level regard a STEM-oriented study track in secondary school as a mandatory prerequisite to be accepted in the bachelor's program. We, therefore, only included students that followed such a STEM-oriented track, in which mathematics, physics, chemistry, and biology are mandatory subjects.

Secondary schools within the district and the network of our university were approached by the researchers and informed about the goal and procedure of the research. Four schools from other parts of the country contacted the researchers after hearing about the research and expressed an interest to participate. Out of the 15 schools that expressed initial interest, 11 eventually agreed to participate. When a school expressed interest, all students in our target group and their parents were 
informed about the research and asked for consent. Students were asked for active informed consent and their parents for passive informed consent. Parents received a letter from their school (by email and a paper version) containing information about the research project and that participation was voluntary and were asked whether their son or daughter was willing to and had permission to participate. They were also informed that they could object to participation by simply replying to the email without having to explain in any way why they objected. Five parents objected to participation. This passive /active consent procedure was chosen in consultation with the school principals, who advised us against pursuing active consent from the parents. When informed consent was obtained, students filled in an online or paperand-pencil version of the questionnaire (depending on the facilities at school). Students' grades were obtained from the school (also with active consent from the students and passive consent from the parents). After combining students' grades and their questionnaire data, all personal information was deleted and the dataset was analyzed anonymously. The ethics committee of the university approved these procedures.

\section{Instruments}

A Likert-type 4-point scale questionnaire was used to assess students' implicit STEM ability beliefs, general ability beliefs, STEM self-efficacy beliefs, and the intention to opt for a STEM degree (STEM intention). All subscales were forcedchoice and had four response options [fully agree (1) to fully disagree (4)]. Subjects' grades on the STEM subjects of mathematics, physics, chemistry, and biology were obtained from the school. The order of the items was randomized in the questionnaire.

Implicit STEM ability beliefs. The scale used to measure implicit STEM ability beliefs was based on the translation of the Self-theory scale by De Castella and 
Implicit beliefs and STEM choice

Byrne (2015). This revised self-theory measure of implicit ability beliefs assesses students' beliefs about their ability to change their own ability in contrast to their beliefs about the malleability of intelligence in general, as it is measured by Dweck's original scale (Dweck, 2000). After translation, the eight original items were rephrased so that they did not question beliefs about general intelligence but beliefs about STEM ability, for example 'I believe I can always substantially improve on my STEM ability'. In order to be able to assess discriminant validity of our STEM scale compared to the original 'general intelligence scale', we also included the Dutch translations of the original scale by De Castella and Byrne (2015), e.g., 'I believe I can always substantially improve on my intelligence'. Table 1 shows an overview of the subscales and items of the STEM beliefs subscale (seven items) and the general beliefs subscale (eight items) after the validity analyses.

Domain-specific self-efficacy. The STEM-oriented self-efficacy beliefs subscale was based on the self-efficacy subscale of the Patterns of Adaptive Learning Scale (PALS) (Midgley et al., 2000), a validated instrument. The PALS has been developed to examine the relation between the learning environment and students' motivation, affect, and behaviour. The efficacy scale measures students' perceptions of their competence to do their class work. The five items were translated into Dutch and rephrased to address students' beliefs about their self-efficacy in STEM subjects at school, for example 'I'm certain I can master the skills taught in STEM classes'.

STEM intention ${ }^{1}$. STEM intention was measured with six items: three reflecting a positive intention and three reflecting a negative intention to choose a

${ }^{1}$ Students' actual choice for a bachelor's degree is dependent on a multitude of factors and the actual choice does not reflect the possible considerations leading up to this choice. We, therefore, measured students' current intention to opt for a STEM degree after high school and not their actual choice. 
STEM degree. The items were formulated in the following way: A header stated:

'When I pursue a bachelor's degree next year, I ...', followed by the six items, such as: ' ...intend to choose a STEM field-oriented degree'.

STEM achievement. STEM achievement was indicated by students' grades in the four STEM subjects: mathematics, physics, chemistry and biology. Grades were obtained from school records and represented the average grade of the students over the last half year of school in each subject. We included this achievement measure as a latent variable in the models, which was indicated by students' grades on the four STEM subjects.

\section{Data Analyses Strategy}

To investigate our research questions, we analyzed the data with Structural Equation Modelling (SEM). SEM is a collection of statistical techniques that can be used to examine the relations between a group of independent and dependent variables, and to reduce the number of observed variables into a smaller number of latent variables. This technique allows one to examine the fit of an unrestricted factor structure to the acquired data, the fit of a theoretically informed model to the acquired data, or to compare the fit of two theoretically informed models. All analyses were performed using Mplus7 software, version 1.4 (Muthén \& Muthén, 1998-2015). The missing values were handled in a pairwise manner. Before the analyses, the negatively phrased items of the STEM intention scale, and the general and STEM beliefs scales were reverse coded. Because our data were Likert-type 4-point scale scores, we defined implicit beliefs, self-efficacy, and STEM intention as ordinal variables in our analyses. The default estimator used to analyze categorical or ordinal variables is the robust weighted least squares estimator (WLSMV) (Brown, 2006; 
Muthén \& Muthén, 1998-2015). Achievement was defined as a continuous variable, since it was based on average grades ranging from 0 to 10 .

The goodness-of-fit of the models was evaluated on the basis of the combination of the values of the Root Mean Square Error of Estimation (RSMEA), the Comparative Fit Index (CFI), and the Tucker-Lewis Index (TLI) (Schreiber, Nora, Stage, Barlow, \& King, 2006). A good model fit is indicated by RSMEA values of 0.05 or less, and CFI and TLI values greater than 0.95 for continuous and categorical outcomes (Hu and Bentler, 1999; Schermelleh-Engel \& Moosbrugger, 2003). A moderate or acceptable model fit is indicated by RSMEA values below 0.08 and CFI and TLI values between 0.90 and 0.95 (Hu and Bentler, 1999; Schermelleh-Engel \& Moosbrugger, 2003). Furthermore, we assessed model fit by the fit index $\chi^{2} / d f$, for which values less than 3 indicate good model fit, and values less than 5 an acceptable fit (Schermelleh-Engel \& Moosbrugger, 2003). Non-nested models were compared on the basis of the aforementioned goodness-of fit-values. Nested models were compared with Chi-square difference tests, using the WLSMV estimator (Muthén \& Muthén, 1998-2015).

\section{Assessing the quality and dimensionality of the STEM ability beliefs}

construct. Several steps were taken to examine the quality and dimensionality of the STEM ability beliefs scale before running the main analyses on the data. A first exploration of the data was conducted using Exploratory Factor Analysis (EFA), which examines the unrestricted factor structure of observed variables (items) in the dataset. The goal of the EFA was threefold. First, it allowed us to examine whether the items representing our different theoretical constructs clustered as intended. Second, it allowed us to examine whether the construct of STEM beliefs could indeed be considered as an independent factor from general intelligence beliefs. And third, it 
indicated whether entity beliefs and incremental beliefs should be regarded as one dimension or two dimensions in our data analyses. If entity and incremental items loaded on the same factor, this would provide support for the homogeneity of the construct, at least in our present data set. If not, it would provide support for the multidimensionality of the construct. A maximum number of eight factors was preset. The resulting factor structure - including the general beliefs scale - was subsequently analyzed using Confirmatory Factor Analysis (CFA) to examine how well the observed data fit the pre-defined hypothesized factor structure (see The current study section).

To assess the convergent and discriminant validity of the two implicit beliefs subscales (STEM beliefs and General ability beliefs), we calculated measures of Average Variance Extracted (AVE), Average Shared Variance (ASV), and Maximum Shared Variance (MSV) based on the CFA coefficients (Carter, 2016). Convergent validity of a subscale is considered satisfactory when AVE is equal to or greater than .50 , i.e., the amount of shared variance among items that belong to a subscale. Discriminant validity of a subscale is met when the AVE of a subscale is greater than the Average Shared Variance (ASV) between this subscale and a related subscale and greater than the MSV. The subscales' internal consistency was assessed using Cronbach's alpha.

\section{Investigating the relation between implicit STEM ability beliefs, STEM} self-efficacy and STEM intention. We used SEM analysis to investigate the structural relations in the STEM intention model (without the general beliefs construct). To examine the research questions, a two-step procedure was taken; first testing the measurement model using Confirmatory Factor Analysis (CFA) and subsequently testing a structural model using SEM analysis. A measurement model 
Implicit beliefs and STEM choice

describes the latent factor structure of the model and relates the measured variables (in this case the items of the questionnaire) to the latent factors (such as self-efficacy).

The Structural Model describes the hypothesized relationships among the latent variables or constructs, such as the relation between the latent factors Implicit STEM ability beliefs and Self-efficacy. We examined three structural models on the basis of our research questions (see Figure 1 for the three models). The first research question concerned whether implicit STEM ability beliefs are related to STEM intention. This was examined using a Direct Effect model, controlling for achievement by including it as an exogenous variable. For the second research question, we tested the hypothesized mediating role of self-efficacy in the relation between implicit STEM ability beliefs and STEM intention. To achieve this we compared, using $\chi^{2}$ difference testing for nested models, the partial mediation model (full model) with the complete mediation model, where the direct path between implicit beliefs and STEM intention was constrained to zero.

----Insert Figure 1 about here----

\section{Results}

One participant was identified and removed from the dataset because there was no variation in responses (even on positively and negatively stated items), indicating that this participant was unengaged when filling in the questionnaire. There were 11 participants with 1 missing value, and 6 participants with 2 to 3 missing values, resulting in less than a total of $0.21 \%$ missing values. Reported $\beta$ 's are the standardized estimates. 


\section{Examining the quality and dimensionality of the STEM ability beliefs scale}

The Exploratory Factor Analysis (EFA), using WLSMV and Geomin oblique rotation, resulted in five factors with Eigenvalues above 1, as expected. All items intended to measure a particular latent construct loaded onto one factor, resulting in five factors representing the following constructs: STEM intention, general beliefs, STEM beliefs, self-efficacy, and achievement. All items demonstrated factor loadings greater than .40 and did not show cross-loadings (Worthington \& Whittaker, 2006). Internal consistency analyses of the items in each factor using Cronbach's alpha demonstrated good internal consistency (alphas between .84 and .93). One item showed a suppressive effect on the alpha of the STEM beliefs scale ('I have a certain amount of STEM aptitude, and I really can't do much to change it') and one similar item showed a similar suppressive effect on the alpha of the general beliefs scale ('I have a certain amount of intelligence, and I really can't do much to change it'). These items were removed from the dataset, resulting in a scale for STEM beliefs consisting of 7 items, and a general beliefs scale consisting of 8 items. The EFA on the adjusted dataset resulted in the same results; five factors with factor loadings greater than .40 and no cross-loadings (see Table 1). Factor loadings ranged between .52 and .97 . The resulting model fit was adequate $\left(\chi^{2} / d f=3.59, C F I=.965, T L I=.949\right.$, RMSEA =.078). These results demonstrated that the items measuring the constructs of implicit STEM ability beliefs and general ability beliefs loaded onto different factors, which provided preliminary support for the independence of the construct of STEM ability beliefs.

We performed CFA with WLSMV to assess how well the data fitted the obtained factorial structures that we derived with the EFAs. The CFA confirmed the fit of the model structure to the data $\left(\chi^{2} / \mathrm{df}=2.50, \mathrm{CFI}=.973, \mathrm{TLI}=.971\right.$, 
Implicit beliefs and STEM choice

RMSEA $=.056)$ and supported the construct validity of the STEM beliefs scale compared to the general beliefs scale.

The factor correlation matrix demonstrated that the STEM ability beliefs and general ability beliefs subscales were moderately correlated $(r=.62)$. The AVE values for the STEM beliefs scale $(\mathrm{AVE}=.56)$ and the General beliefs scale $(\mathrm{AVE}=$ .73) indicated sufficient convergent validity for both subscales. The discriminant validity of the subscales was further supported by AVE values that exceeded ASV (0.48) and MSV (0.48) of these subscales. These results supported the assumption that implicit STEM ability beliefs constitute a separate latent construct compared to general ability/intelligence beliefs.

Furthermore, both EFA and CFA suggested that the construct of implicit STEM ability beliefs as measured in our data should be regarded as a onedimensional construct in our SEM analyses, since both the entity and incremental STEM belief items loaded onto the same implicit STEM ability factor. Since we cannot deduct from the literature to date whether to use a multi-dimensional or a onedimensional construct for implicit ability beliefs, based on our current data, we decided that the one-dimensional construct of implicit STEM ability beliefs was the preferred construct to use for our present investigation of the relation between implicit STEM ability beliefs and STEM intention.

---Insert Table 1 around here---

Descriptive statistics and correlations. We investigated the relation between the latent variables implicit STEM ability beliefs, STEM self-efficacy beliefs, STEM achievement, and STEM intention. Descriptive statistics of the observed variables and their correlations are presented in Table 2. As expected, we found significant positive correlations between implicit STEM ability beliefs, STEM self-efficacy, and STEM 
intention. We did not find a significant correlation between STEM achievement and implicit STEM ability beliefs. The correlation between the mean scores on the entity items (non-reversed) and the incremental items was -.69, which corresponds to the higher values in the range of correlations reported by previous studies (see Tempelaar et al., 2015 for an overview).

---Insert Table 2 around here---

\section{STEM intention: Measurement model}

The measurement model demonstrated an acceptable fit to the data, see Table 3. All observed variables in the model loaded onto the respective latent variables and all factor loadings were significant $(p<.001)$, ranging from .55 to .97 . We did not conduct post-hoc modifications to any of the models because of the relatively good fit of the model to the data.

\section{STEM intention: SEM}

To investigate the structural relations between the latent variables and the mediation effects, we conducted three SEM analyses. First, the Direct Effects model was tested (Figure 1a). The Direct Effects model demonstrated a poor to moderate fit to the data, see Table 3. However, the structural path coefficients were significant $(p \leq$ $.001 ; \beta$ s ranging from .32 to .59 ), with the exception of a non-significant path between STEM intention and STEM achievement $(\beta=.06, p=.21)$. These results suggest a direct relation between implicit STEM ability beliefs and STEM intention $(\beta=.32, p$ $\leq .001)$

Second, we investigated whether this relation was mediated by STEM selfefficacy beliefs. To that end, the partial mediation model was tested, see Figure $1 \mathrm{~b}$ (this is also called a full model, since it contains all paths between the latent factors). The partial mediation model demonstrated an acceptable to good fit to the data (Table 
Implicit beliefs and STEM choice

3 ). The structural path coefficients were significant $(p \leq .001 ; \beta$ s ranging from .09 to

.54). The coefficient for the direct relation between implicit STEM ability beliefs and

STEM intention decreased compared to the Direct effects model, but was still significant $(\beta=.14, p=.004)$.

Third, we compared the fit of this partial mediation (full) model to a more parsimonious model in which the direct relation between implicit STEM ability beliefs and STEM intention was constrained to zero (Figure 1c). When these nested models significantly differ from one another, we can assume that the full model (partial mediation) explains the data better. When no significant difference is found between these models, then we accept that the most parsimonious model (complete mediation) explains the data equally well and is, therefore, the preferred model. If complete mediation is not shown, partial mediation can still be demonstrated when the direct effect is reduced but is still greater than zero after inclusion of the mediator (Speybroek et al., 2012).

The constrained, complete mediation model also showed an acceptable to good fit to the data. The $\chi^{2}$ difference test for nested models demonstrated a significant difference between the models $\left(\chi^{2}=8.24, d f=1, p=.004\right)$, thus the partial mediation model (Figure 1c and Figure 2) explained the data significantly better than the complete mediation model. Partial mediation was also supported by the reduced, but still significant, direct path coefficients between implicit STEM ability beliefs and STEM intention in the partial mediation model compared to the Direct effects model (changing from $\beta=.32$ in the direct effect model to $\beta=.14$ in the partial mediation model).

Overall, these results indicated that STEM self-efficacy partially mediates the relation between implicit beliefs about the malleability of STEM ability and the 
intention to opt for a STEM degree. The structured standardized path coefficients of the partial mediation model are depicted in Figure 2. With this model structure, 39.2 $\%$ of the variance in the intention to opt for a STEM bachelors' degree was explained.

---Insert Figure 2 and Table 3 around here----

\section{Discussion}

The goal of the current study was to examine the relationship between students' implicit beliefs about the malleability of their STEM abilities, their STEM self-efficacy beliefs, and their intention to opt for a STEM field bachelor's degree after graduating from high school. The results demonstrated that domain-specific implicit beliefs about the malleability of STEM ability significantly predicted students' intention to opt for a STEM field career. Furthermore, the results suggested that part of the mechanism via which implicit STEM beliefs affect STEM intention is through STEM self-efficacy beliefs. A stronger belief in the malleability of your STEM ability predicts stronger STEM self-efficacy beliefs, and these in turn relate to a stronger intention to opt for a STEM field bachelor's degree. These findings could be key in efforts to increase the inflow of students into the STEM field. An explicit focus on stimulating incremental beliefs about STEM ability could stimulate positive self-efficacy beliefs in the STEM field and subsequently increase students' intention to opt for a STEM career.

Our data provided no evidence for using a multi-dimensional construct for implicit beliefs of STEM ability. We therefore used a one-dimensional construct in our SEM-analyses, which is in line with the prevailing approach of using a onedimensional construct for research on implicit beliefs about learning ability. 
Implicit beliefs and STEM choice

\section{The relation between implicit STEM ability beliefs, STEM self-efficacy, and}

\section{STEM intention}

This study provides the first empirical support for the idea that implicit beliefs about STEM ability predict students' intention to opt for a STEM bachelor's degree. Our findings furthermore support the hypothesized assumption that self-efficacy beliefs mediate the relation between implicit beliefs and STEM intention (van Aalderen-Smeets \& Walma van der Molen, 2016). Consistent with previous research, we found that the more students endorsed incremental beliefs about their STEM ability, the more positive STEM self-efficacy beliefs they reported (Robin \& Pals, 2002). In addition, the more students endorsed positive STEM self-efficacy beliefs, the more likely they were to opt for a STEM degree, which is also consistent with previous research (Betz \& Hackett, 1983; Borgen \& Betz, 2008; O’Brien, MartinezPons, \& Kopala, 1999; Wigfield \& Eccles, 2000).

However, the relation between implicit beliefs and self-efficacy might not be that straightforward. It is not necessarily the case that incremental beliefs predict more positive self-efficacy beliefs. It is more likely that incremental beliefs protect an individual from decreases in self-efficacy when encountering setbacks and failure (Erdley, Cain, Loomis, Dumas-Hines, \& Dweck, 1997; Henderson \& Dweck, 1990; Hong, Chiu, Dweck, Lin, \& Wan, 1999; Niiya, Crocker, \& Bartmess, 2004; Robin and Pals, 2002). Students who hold stronger entity beliefs, are more likely to attribute failure to a lack in ability, while students holding stronger incremental beliefs are more likely to attribute failure to a lack in effort, which is less likely to influence selfefficacy beliefs. As long as there has been no setback or failure in one's life (which is rare), a student's implicit beliefs will not influence his or her self-efficacy beliefs. This is consistent with Robin and Pals (2002), who showed that during four years in 
college, students holding stronger entity beliefs were more vulnerable to declines in self-efficacy.

The current study's participants already had five years of experience with STEM school subjects demanding a high level of difficulty and we assume that they probably encountered one or more setbacks or failures during these years, except maybe for a few very academically advanced students. We assume that students' implicit beliefs influenced their interpretation of and reactions to setbacks in the STEM domains (such as attribution of a failure) and may thereby have shaped their STEM self-efficacy beliefs accordingly. These STEM self-efficacy beliefs, probably in combination with other factors that may influence students' theories about their abilities (such as beliefs in effort, learning goals, coping mechanisms, and achievement (Blackwell et al., 2007; Dweck, 2000)) are likely to affect their intention to opt for a STEM degree. Students who do not decline in self-efficacy beliefs regarding STEM subjects when faced with challenges or setbacks are more likely to keep the option for enrolling in a STEM field degree open, while students who believe they are less able to succeed in STEM school subjects (independent of achievement) may exclude the option for a STEM degree. However, these assumptions were not tested in the current study; future longitudinal studies should address the causality of the relation between these factors.

Our results also demonstrated that STEM self-efficacy beliefs partially mediated the relation between implicit STEM ability beliefs and STEM intention. There is theoretically no reason to assume a direct relation between implicit STEM ability beliefs and STEM intention; a student's belief that STEM aptitude is malleable, does not necessarily predict that this student will choose a STEM degree. It is more likely that there are additional variables - besides STEM self-efficacy - which 
Implicit beliefs and STEM choice

mediate the relation between implicit STEM ability beliefs and STEM intention, such as stereotypical beliefs and motivational factors (e.g., achievement goals), as suggested by van Aalderen-Smeets and Walma van der Molen (2016). Future research could test more elaborate STEM intention models, including additional variables such as gender-stereotypical beliefs and goal achievement.

Our findings support previous literature that shows that self-efficacy is a very salient factor influencing STEM intentions, (e.g., Wigfield \& Eccles, 2000). Bandura (1977) stated that self-efficacy beliefs are derived from different experiences or types of information that a student encounters and that it is the appraisal or interpretation of these experiences that determines self-efficacy. Many interventions aiming at stimulating positive self-efficacy beliefs focus on providing one or more of the four experiences suggested by Bandura (performance accomplishments, vicarious experiences, verbal persuasion, and physiological states). The current findings indicate that students' implicit beliefs may determine how these experiences are appraised and that this might be a valuable contribution to the self-efficacy theory itself and to interventions aiming to stimulate positive self-efficacy beliefs.

In our model, 39\% of the variance in STEM intention was explained, which might not seem very high. However, the intention to opt for a STEM bachelor's degree may be influenced by a multitude of factors, such as social-economic factors, cultural factors, or educational factors (van Tuijl \& Walma van der Molen, 2016; Wang \& Degol, 2013). A student's implicit STEM ability belief is just one of the factors contributing to the intention to opt for a particular study path. It would, therefore, be unlikely to expect that implicit STEM ability beliefs explain a large amount of the variance in STEM intention.

\section{Achievement}


Contrary to previous findings (Rask, 2010; Wang, 2012), we did not observe a very strong relation between STEM grades and STEM intention in the structural model. This relation was, however, present in the correlation analyses and in the Direct-effects model, but became just barely significant when adding STEM selfefficacy to the model. One explanation could be that STEM self-efficacy beliefs serve as a tertium quid in this relation - a third variable influencing both achievement and STEM intention that could explain the observed correlation between the other two variables.

Achievement did not seem to influence the relation between STEM selfefficacy and STEM intention, since these relations were present while controlling for achievement. Although having good grades in a subject or domain is favorable when opting for a bachelor's degree in this field, good grades do not necessarily determine the field that will be chosen, since students might have good grades in other domains as well, or might just have strong motivation/interest for another field of study.

\section{Limitations and future research}

The current study's limitations need to be addressed in future research. First, for practical reasons, we were only able to investigate a limited number of factors that may contribute to the mechanism underlying one's decision-making process in the STEM domain. We know from the literature that there are many contextual factors that may influence STEM career decisions and that there is a more complex system of beliefs underlying these decisions (Eccles, 1994; van Tuijl \& Walma van der Molen, 2016; Wang \& Degol, 2013). Focusing on a single factor does not provide a comprehensive overview of the whole mechanism contributing to STEM intention. However, focusing on a single mechanism may provide a clearer view of the specific 
Implicit beliefs and STEM choice

contribution of this variable. This is preferable when investigating the contribution of a new hypothesized factor, which was the aim of the present study.

Second, the findings are based on students' self-reports. This is the common methodology for measuring implicit ability beliefs and self-efficacy, but it might provoke socially desirable responses. Unfortunately, there are no implicit measures of ability beliefs, such as implicit association tests, available yet.

Nevertheless, our study's findings are noteworthy, particularly given the lack of empirical research on the relation between implicit STEM ability beliefs and STEM career choice. The current findings open the way to examine a new approach to stimulate students' self-efficacy beliefs within the STEM field.

As several studies have shown, small-scale interventions aiming to stimulate incremental beliefs can be effective in improving secondary school students' achievement (Blackwell et al., 2007; Paunesku et al., 2015), in improving processes underlying cognitive control (Schroder et al., 2014), and in improving mathematics motivation (Blackwell et al., 2007). Note, however, that there are also studies that did not find an effect of interventions on motivational measures and performance (Dommet, Devonshire, Sewter \& Greenfield, 2013). Although short-term interventions are preferred from a practical point of view, long-term interventions might be more effective. We argue that the mechanism via which implicit beliefs about ability influence self-efficacy beliefs develops over a longer time-span, and exerts its effect mostly in situations that are experienced as a setback, a failure, or when people have to make a choice to take on a challenge. The most effective intervention would target implicit beliefs and the subsequent self-efficacy and effort beliefs at the time of the experienced setback, directly at that moment. Teachers could intervene during these moments by providing feedback that stimulates incremental 
beliefs, by asking questions to make students aware of their self-disadvantaging response to failure, or by helping students in coping with challenges in a positive way. This calls for evidence-informed teacher professional development programs.

\section{Conclusion}

The present study provides the first piece of empirical evidence that implicit beliefs about the malleability of STEM ability may play an important role in the mechanism underlying students' intentions to opt for a STEM study path. An important part of the underlying mechanism is the mediating role of STEM selfefficacy beliefs. The current findings suggest that if teachers and schools can stimulate more incremental beliefs about STEM ability in their students, this may have a positive effect on students' self-efficacy beliefs regarding STEM, and subsequently on their intention to opt for a STEM study path. Interventions aiming to boost STEM self-efficacy beliefs should, therefore, include stimulating incremental beliefs about the malleability of STEM ability. These findings present a novel way to look at the motivation and interest of students for the STEM field. It shows that it is not just STEM ability itself that determines students' potential career in the STEM field, but that it is their perception of the malleability of their STEM abilities that might play an even bigger role.

Acknowledgement. We would like to thank Eline Meijerink, Carlijn Veldhorst, and Kim Vissers for their help and support in this project. 
Implicit beliefs and STEM choice

\section{References}

Aronson, J., Fried, C. B., \& Good, C. (2002). Reducing the effects of stereotype threat on African American college students by shaping theories of intelligence. Journal of Experimental Social Psychology, 38, 113-125. Doi: 10.1006/jesp.2001.1491.

Bahník, S. \& Vranka, M., A. (2017). Growth mindset is not associated with scholastic aptitude in a large sample of university applicants. Personality and Individual Differences, 117, 139-143.

Bandura, A. (1997). Self-efficacy: The exercise of control. New York: Freeman.

Bandura, A. (2006). Going global with social cognitive theory: From prospect to paydirt. In S. I. Donaldson, D. E. Berger \& K. Pezdek (Eds.), The rise of applied psychology: New frontiers and rewarding careers (pp. 53-70). Mahwah, NJ: Erlbaum.

Betz, N. E., \& Hackett, G. (1983). The relationship of mathematics self-efficacy expectations to the selection of science-based college majors. Journal of Vocational Behavior, 23, 329-345. Doi: 10.1016/0001-8791(83)90046-5.

Blackwell, L. S., Trzesniewski, K. H., \& Dweck, C. S. (2007). Implicit theories of intelligence predict achievement across an adolescent transition: A longitudinal study and an intervention. Child Development, 78, 246-263. Doi: 10.1111/j.1467-8624.2007.00995.x.

Borgen, F. H., \& Betz, N. E. (2008). Vocational self-efficacy and personality: Linking vocational confidence and the healthy personality. Journal of Vocational Assessment, 16, 22-43. Doi: 10.1177/1069072707305770.

Bøe, M. V., Henriksen, E. K., Lyons, T., \& Schreiner, C. (2011). Participation in science and technology: Young people's achievement-related choices in latemodern societies. Studies in Science Education, 47, 37-72. Doi: 10.1080/03057267.2011.549621.

Brown, T. (2006). Confirmatory factor analysis for applied research. New York: Guildford

Burke, L. A., \& Williams, J. M. (2012). The impact of a thinking skills intervention on children's concepts of intelligence. Thinking Skills and Creativity, 7, 145-152. Doi: $10.1016 /$ j.tsc.2012.01.001.

Burkley, M., Parker, J. S., Stermer, P., \& Burkley, E. (2010). Trait beliefs that make women vulnerable to math disengagement. Personality and Individual Differences, 48, 234-238. Doi: 10.1016/j.paid.2009.09.002.

Burnette, J. L., O’Boyle, E. H., VanEpps, E. M., Pollack, J. M., \& Finkel, E. J. (2013). Mind-sets matter: A meta-analytic review of implicit theories and selfregulation. Psychological Bulletin, 139, 655-701. Doi:10.1037/a0029531.

Carter, S. R. (2016). Using confirmatory factor analysis to manage discriminant validity issues in social pharmacy research. International Journal of Clinical Pharmacy, 38, 731-737. Doi: 10.1007/s11096-016-0302-9.

Claro, S., Paunesku, D., \& Dweck, C. S. (2016). Growth mindset tempers the effects of poverty on academic achievement. PNAS, 113(31). Doi: 10.1073.

Cohen, J. (1992). A power primer. Psychological Bulletin, 112, 155-159.

De Castella, K. \& Byrne, D. (2015). My intelligence may be more malleable than yours: the revised implicit theories of intelligence (self-theory) scale is a better predictor of achievement, motivation, and student disengagement. European 
Journal of Psychology and Education, 30, 245-267. Doi: 10.1007/s10212-0150244-y.

DeWitt, J. \& Archer, L. (2015). Who aspires to a science career? A comparison of survey responses from primary and secondary school students. International Journal of Science Education, 37, 2170-2192. Doi: 10.1080/09500693.2015.1071899.

Dommett, E. J., Devonshire, I. M., Sewter, E., \& Greenfield, S. A. (2013). The impact of participation in a neuroscience course on motivational measures and academic performance. Trends in Neuroscience and Education, 2, 122-138. doi:10.1016/j.tine.2013.05.002.

Dupeyrat, C. \& Mariné, C. (2005). Implicit theories of intelligence, goal orientation, cognitive engagement, and achievement: A test of Dweck's model with returning to school adults. Contemporary Educational Psychology, 30, 43-59. Doi: 10.1016/j.cedpsych.2004.01.007.

Dweck, C. S. (2000). Self-theories: Their role in motivation, personality, and development. Philadelphia: Psychology Press.

Dweck, C. S. (2006). Is math a gift? Beliefs that put females at risk. In S. J. Ceci \& W. Williams (Eds.) (2006). Why aren't more women in science? Top researchers debate the evidence. American Psychological Association, Washington, DC.

Dweck, C. S. (2008). Mindsets and math/science achievement. New York: Carnegie Corporation of New York, Institute for Advanced Study, Commission on Mathematics and Science Education.

Eccles, J. S. (1994). Understanding women's educational and occupational choices. Psychology of Women Quarterly, 18, 585-609. doi:10.1111/j.14716402.1994.tb01049.x.

Erdley, C. A., Cain, K. M., Loomis, C. C., Dumas-Hines, F., \& Dweck, C. S. (1997). Relations among children's social goals, implicit personality theories, and responses to social failure. Developmental Psychology, 33, 263-272. Doi:10.1037/0012-1649.33.2.263.

Fadlelmula, F.K. (2010). Educational motivation and students' achievement goal orientations. Procedia Social and Behavioral Sciences 2, 859-863, Doi: 10.1016/j.sbspro.2010.03.116

Glynn, S. M., Brickman, P., Armstrong, N., \& Taasoobshirazi, G. (2011). Science motivation questionnaire II: Validation with science majors and nonscience majors. Journal of Research in Science Teaching, 48, 1159-1176. Doi: 10.1002/tea.20267.

Henderson, V. L. \& Dweck, C. S. (1990). Achievement and motivation in adolescence: A new model and data. In S. Feldman \& G. Elliott (Eds.) At the threshold: The developing adolescent. Cambridge, MA: Harvard University Press.

Hong, Y. Y., Chiu, C. Y., Dweck, C. S., Lin, D., \& Wan, W. (1999). Implicit theories, attributions, and coping: A meaning system approach. Journal of Personality and Social Psychology, 77, 588-599. Doi: 10.1037/0022-3514.77.3.588.

Hu, L., \& Bentler, P. M. (2009). Cutoff criteria for fit indexes in covariance structure analysis: Conventional criteria versus new alternatives. Structural Equation Modeling: A Multidisciplinary Journal, 6, 1-55. Doi: 10.1080/10705519909540118.

Jonsson, A, Beach, D., Korp, H., \& Erlandson, P. (2012). Teachers' Implicit Theories of Intelligence: Influences from Different Disciplines and Scientific Theories. 
Implicit beliefs and STEM choice

European Journal of Teacher Education, 35, 387-400. Doi: dx.doi.org/10.1080/02619768.2012.662636.

Mascret, N., Falconetti, J., \& Cury, F. (2016). Implicit measures of beliefs about sport ability in swimming and basketball. European Journal of Sport Science, 16, 358-64. Doi: 10.1080/17461391.2015.1080304.

Midgley, C. et al. (2000). Manual for the patterns of adaptive learning scales. Publication of the University of Michigan, Ann Arbor, MI, USA. Retrieved from umich.edu/ pals/PALS\%202000_V13Word97.pdf on February $21^{\text {st }}$ 2017.

Midgley, C. (Ed.) (2002). Goals, goal structures, and patterns of adaptive learning. Mahwah, NJ: Erlbaum

Murphy, L., \& Thomas, L. (2008). Dangers of a fixed mindset: Implications of selftheories research for computer science education. ACM SIGCSE Bulletin, 40, 271-275. Doi: 10.1145/1597849.1384344.

Muthén, L.K. \& Muthén, B.O. (1998-2015). Mplus User's Guide. Seventh Edition. Los Angeles, CA: Muthén \& Muthén.

Niiya, Y., Crocker, J., \& Bartmess, E. N. (2004). From vulnerability to resilience: Learning orientations buffer contingent self-esteem from failure. Psychology Science, 15, 801-805. Doi: 10.1111/j.0956-7976.2004.00759.x.

Nix, S., Perez-Felkner, L., \& Thomas, K. (2015). Perceived mathematical ability under challenge: A longitudinal perspective on sex segregation among STEM degree fields. Frontiers in Psychology, 6, 530. Doi: 10.3389/fpsyg.2015.00530.

O’Brien, V., Martinez-Pons, M., \& Kopala, M. (1999). Mathematics self-efficacy, ethnic identity, gender, and vocational interests related to mathematics and science. The Journal of Educational Research, 92, 231-235. Doi: $10.1080 / 00220679909597600$

OECD (2017). Education at a Glance 2017: OECD Indicators. Paris: OECD Publishing, http://dx.doi.org/10.1787/eag-2017-en.

Osborne, J., \& Dillon, J. (2008). Science education in Europe: Critical reflections (a report). London: the Nuffield Foundation. http://www.polleneuropa.net/pollendev/ImagesEditor/Nuffieldreport.pdf.

Patterson, M. M., Kravchenko, N., Chen-Bouck, L., \& Kelley, J. (2016). General and domain-specific beliefs about intelligence, ability, and effort among preservice and practicing teachers. Teaching and Teacher Education 59:180-190. Doi: 10.1016/j.tate.2016.06.004.

Paunesku, D., Walton, G. M., Romero, C., Smith, E. N., Yeager, D. S., \& Dweck, C. S. (2015). Mind-set interventions are a scalable treatment for academic underachievement. Psychological Science, 26, 784-793. Doi: $10.1177 / 0956797615571017$.

Rattan, A., Good, C., \& Dweck, C. S. (2012). "It's ok - Not everyone can be good at math": Instructors with an entity theory comfort (and demotivate) students. Journal of Experimental Social Psychology, 48, 731-737. Doi: 10.1016/j.jesp.2011.12.012.

Rask, K. (2010). Attrition in STEM fields at a liberal arts college: The importance of grades and pre-collegiate preferences. Economics of Education Review, 29, 892-900. Doi: 10.1016/j.econedurev.2010.06.013.

Regan, E., \& DeWitt, J. (2015). Attitudes, interest and factors influencing STEM enrolment behaviour: An overview of relevant literature. In E.K. Henriksen, J. Dillon, \& J. Ryder (Eds.), Understanding student participation and choice in science and technology education (pp. 63-88). Dordrecht: Springer. 
Robins, R. W., \& Pals, J. L. (2002). Implicit self-theories in the academic domain: Implications for goal orientation, attribution, affect, and self-esteem change. Self and Identity, 1, 313-336. Doi: 10.1080/1529886029010680 5.

Rosenzweig, E. Q. \& Wigfield, A. (2016) STEM motivation interventions for adolescents: A promising start, but further to go, Educational Psychologist, 51:2, 146-163, Doi: 10.1080/00461520.2016.1154792

Schermelleh-Engel, K., \& Moosbrugger, H. (2003). Evaluating the fit of structural equation models: Tests of significance and descriptive goodness-of-fit measures. Methods of Psychological Research Online, 8, 23-74.

Schmukle, S. C. \& Egloff, B. (2009). Exploring bipolarity of affect ratings by using polychoric correlations. Cognition and Emotion, 23:2, 272-295, DOI: 10.1080/02699930801987330.

Schreiber, J. B, Nora, A., Stage, F. K., Barlow, E. A., \& King, J. (2006). Reporting Structural Equation Modeling and Confirmatory Factor Analysis Results: A Review, The Journal of Educational Research, 99, 323-338, Doi: 10.3200/ JOER.99.6.323-338.

Schroder, H. S., Moran, T. P., Donnellan, M. B. \& Moser, J. S. (2014). Mindset induction effects on cognitive control: A neurobehavioral investigation. Biological Psychology 103, 27-37. Doi: 10.1016/j.biopsycho.2014.08.004.

Smith, B. P. (2005). Goal orientation, implicit theory of ability, and collegiate instrumental music practice. Psychology of Music, 33, 36 - 57. Doi: $10.1177 / 0305735605048013$.

Susperreguy, M. I., Davis-Kean, P. E., Duckworth, K., \& Chen, M. (2017). Selfconcept predicts academic achievement across levels of the achievement distribution: domain specificity for math and reading. Child Development, Doi: $10.1111 /$ cdev. 12924.

Tempelaar, D. T., Rienties, B., Giesbers, B. \& Gijselaers, W. H. (2015). The pivotal role of effort beliefs in mediating implicit theories of intelligence and achievement goals and academic motivations. Social Psychology of Education, 18, 101-120. Doi: 10.1007/s11218-014-9281-7.

U.S. Congress Joint Economic Committee (2012). STEM Education: Preparing for the Jobs of the Future. Retrieved from: http://www.jec.senate.gov/public/.

Van Aalderen-Smeets, S. I. \& Walma van der Molen, J. H. (2016). Modelling the relation between students' implicit beliefs about their abilities and their educational STEM choices. Journal of Technology and Design Education. Doi: 10.1007/s10798-016-9387-7.

Van Tuij1, C., \& Walma van der Molen, J. H. (2016). Study choice and career development in STEM fields: An overview and integration of the research. International Journal of Technology and Design Education, 26, 159-183. doi:10.1007/s10798-015-9308-1.

Wang, M. T. (2012). Educational and vocational interests in math: A longitudinal examination of the links between classroom environment, motivational beliefs, and interests. Developmental Psychology, 48, 1643-1657. Doi: $10.1037 / \mathrm{a} 0027247$.

Wang, M. T., \& Degol, J. (2013). Motivational pathways to STEM career choices: Using expectancy-value perspective to understand individual and gender differences in STEM fields. Developmental Review, 33, 304-340. Doi: 10.1016/j.dr.2013.08.001.

Watt, H. M. G., Eccles, J. S., \& Durik, A. M. (2006). The leaky mathematics pipeline for girls: A motivational analysis of high school enrolments in Australia and 
Implicit beliefs and STEM choice

the USA. Equal Opportunities International, 25, 642-659, doi: 10.1108/02610150610719119.

Wigfield, A. \& Eccles, J. S. (2000). Expectancy-value theory of achievement motivation. Comtemporary Educational Psychology, 25, 68-81. Doi: 10.1006/ceps.1999.1015.

Worthington, R. L., \& Whittaker, T. A. (2006). Scale development research: A content analysis and recommendations for best practices. The Counseling Psychologist, 34, 806-838. Doi: 10.1177/0011000006288127.

\section{Figure Captions}

Figure 1. Three alternative theoretical STEM intention models depicting associations between implicit beliefs about the malleability of STEM ability (STEM ability beliefs), the intention to opt for a STEM field bachelor's degree, and STEM selfefficacy beliefs. Achievement is a controlling variable.

Figure 2. Structural mediation model of the influence of implicit beliefs about the malleability of STEM ability on STEM related self-efficacy beliefs and the intention to opt for a STEM bachelor's degree. Reported $\beta$ 's are the standardized estimates. Circles present latent variables and rectangles represent measured variables. All italic coefficient (factor loadings) were significant at $p \leq .001$ level.

$* p=.05, * * p<.01, * * * p \leq .001$. 
Table 1

Overview of items used in the questionnaire and construct validation indices for the subscales as obtained by exploratory and confirmatory factor analysis $(N=483)$.

\begin{tabular}{|c|c|c|c|c|c|c|c|c|c|c|}
\hline Items & \multicolumn{5}{|c|}{ EFA } & \multicolumn{5}{|c|}{ CFA } \\
\hline $\begin{array}{l}\text { Intend to choose a degree that doesn't relate to STEM } \\
\text { at all. }\end{array}$ & 0.78 & & & & & 0.82 & & & & \\
\hline $\begin{array}{l}\text { Intend to choose a degree that doesn't require } \\
\text { knowledge about math, science, physics, biology or } \\
\text { other STEM subjects. }\end{array}$ & 0.85 & & & & & 0.86 & & & & \\
\hline Intend to choose a STEM field oriented degree. & 0.76 & & & & & 0.83 & & & & \\
\hline $\begin{array}{l}\text { Intend to choose a degree that requires knowledge } \\
\text { about math, science, physics, biology or other STEM } \\
\text { subjects. }\end{array}$ & 0.72 & & & & & 0.78 & & & & \\
\hline $\begin{array}{l}\text { Intend to choose a degree of which the focus is mainly } \\
\text { on STEM subjects. }\end{array}$ & 0.90 & & & & & 0.89 & & & & \\
\hline $\begin{array}{l}\text { I can learn new things, but I don't have the ability to } \\
\text { change my basic intelligence. }\end{array}$ & & 0.76 & & & & & 0.83 & & & \\
\hline $\begin{array}{l}\text { I don't think I personally can do much to increase my } \\
\text { intelligence. }\end{array}$ & & 0.87 & & & & & 0.81 & & & \\
\hline With enough time and effort, I think I could & & 0.84 & & & & & 0.85 & & & \\
\hline
\end{tabular}


significantly improve my intelligence level.

I believe I can always substantially improve on my

intelligence.

Regardless of my current intelligence level, I think I

have the capacity to change it quite a bit.

I believe I have the ability to change my basic

intelligence level considerably over time.

\section{STEM ability beliefs (SAB)}

I don't think I personally can do much to increase my

STEM abilities

My STEM ability is something about me that I

personally can't change very much.

To be honest, I don't think I can really change my

STEM aptitude.

With enough time and effort, I think I could

I believe I can always substantially improve on my

STEM aptitude.

Regardless of my current STEM ability level, I think I have the capacity to change it quite a bit.

I believe I have the ability to change my basic STEM aptitude level considerably over time.

Self-efficacy (SE)

I'm certain I can master the skills taught in STEM

classes.

I'm certain I can figure out how to do the most

difficult STEM class work.

I can do almost all the work in STEM classes.

I can do even the hardest work in STEM classes if I try. 
STEM achievement (Ach)

Mathematics grade

0.71

0.80

Physics grade

0.83

0.82

Chemistry grade

0.75

Biology grade

Eigenvalues

9.61

5.92

2.50

1.89

AVE

Note:

Factor loadings are only displayed for items with loadings $>.40$. 
Table 2

Descriptives of and Spearmans' rho correlations between the observed variables $(N=483)$.

\begin{tabular}{|c|c|c|c|c|c|c|}
\hline & \multicolumn{3}{|c|}{ Descriptives } & \multicolumn{3}{|c|}{ Correlations } \\
\hline & $\mathrm{M}$ & $\mathrm{SD}$ & \# items & $\begin{array}{l}\text { 1. STEM } \\
\text { ability }\end{array}$ & $\begin{array}{l}\text { 2. STEM } \\
\text { Self- } \\
\text { efficacy }\end{array}$ & $\begin{array}{l}\text { 3. STEM } \\
\text { intention }\end{array}$ \\
\hline $\begin{array}{l}\text { 1. Implicit beliefs about STEM } \\
\text { ability }\end{array}$ & 2.94 & .41 & 7 & $\left(-.69^{*+}\right)$ & & \\
\hline 2. STEM Self-efficacy & 2.64 & .52 & 5 & $.26^{*}$ & & \\
\hline 3. STEM intention & 2.88 & .71 & 6 & $.25^{*}$ & $.51^{*}$ & \\
\hline 4. STEM achievement* & 6.41 & .88 & & -.02 & $.32^{*}$ & $.23^{*}$ \\
\hline
\end{tabular}

${ }^{+}$Correlation between incremental and entity beliefs items within the construct ${ }^{*} \mathrm{p} \leq .001$.

${ }^{* *}$ All scores are measured with a Likert-type 4-point scale from 1 - 4, except achievement, which is measured on a scale from 1-10. 
Table 3

Model fits of the models used to examine the construct validity and the STEM intention model

\begin{tabular}{|c|c|c|c|c|c|c|}
\hline & $\chi^{2}$ & $d f$ & $\chi^{2} / d f$ & CFI & TLI & RMSEA \\
\hline \multicolumn{7}{|l|}{ Examining construct validity } \\
\hline EFA including both STEM and general beliefs & 1058.593 & 295 & 3.59 & .965 & .949 & .078 \\
\hline CFA including both STEM and general beliefs & 984.641 & 395 & 2.50 & .973 & .971 & .056 \\
\hline \multicolumn{7}{|l|}{ Examining the STEM intention model } \\
\hline Measurement Model & 574.863 & 203 & 2.83 & .964 & .960 & .062 \\
\hline Direct Effect model & 862.635 & 205 & 4.21 & .937 & .929 & .081 \\
\hline Self-efficacy as partial mediator (full model) & 576.457 & 204 & 2.83 & .964 & .960 & .061 \\
\hline Self-efficacy as complete mediator & 583.251 & 205 & 2.85 & .964 & .959 & .062 \\
\hline
\end{tabular}


a) Direct effects model

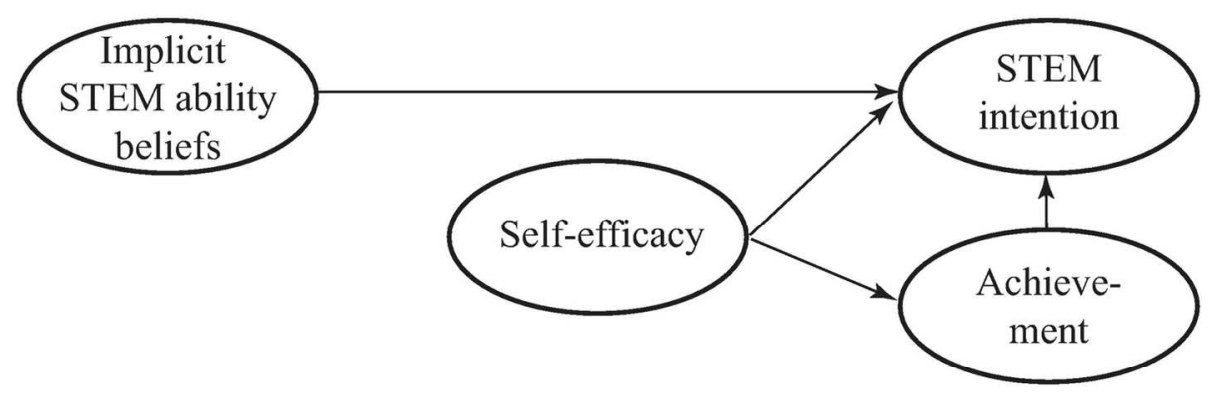

b) Complete mediation model

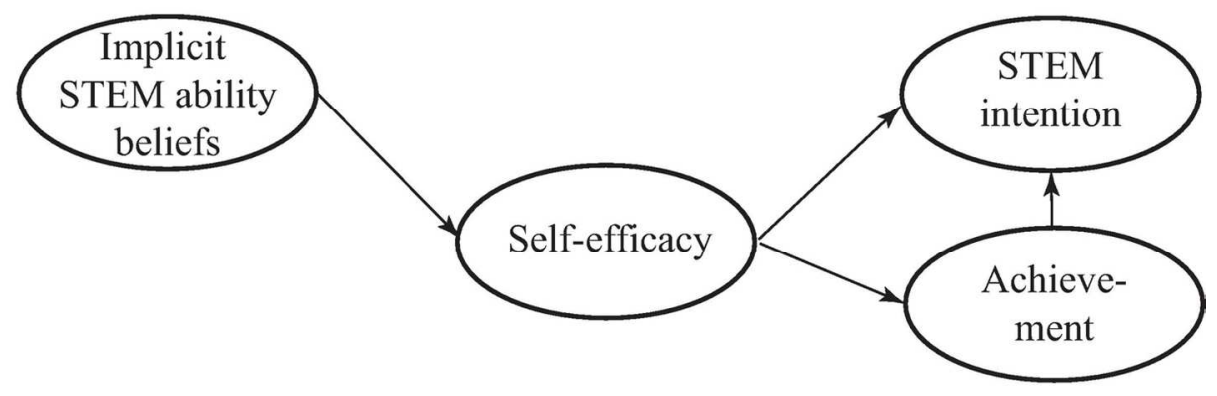

c) Partial mediation model

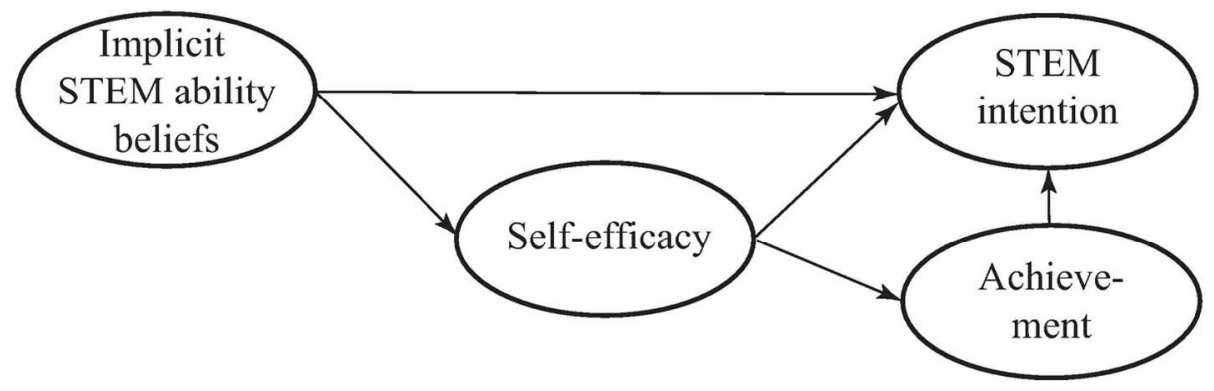

Figure 1. Three alternative theoretical STEM intention models depicting associations between implicit beliefs about the malleability of STEM ability (STEM ability beliefs), the intention to opt for a STEM field bachelor's degree, and STEM self-efficacy beliefs. Achievement is a controlling variable.

$130 \times 159 \mathrm{~mm}(300 \times 300 \mathrm{DPI})$ 


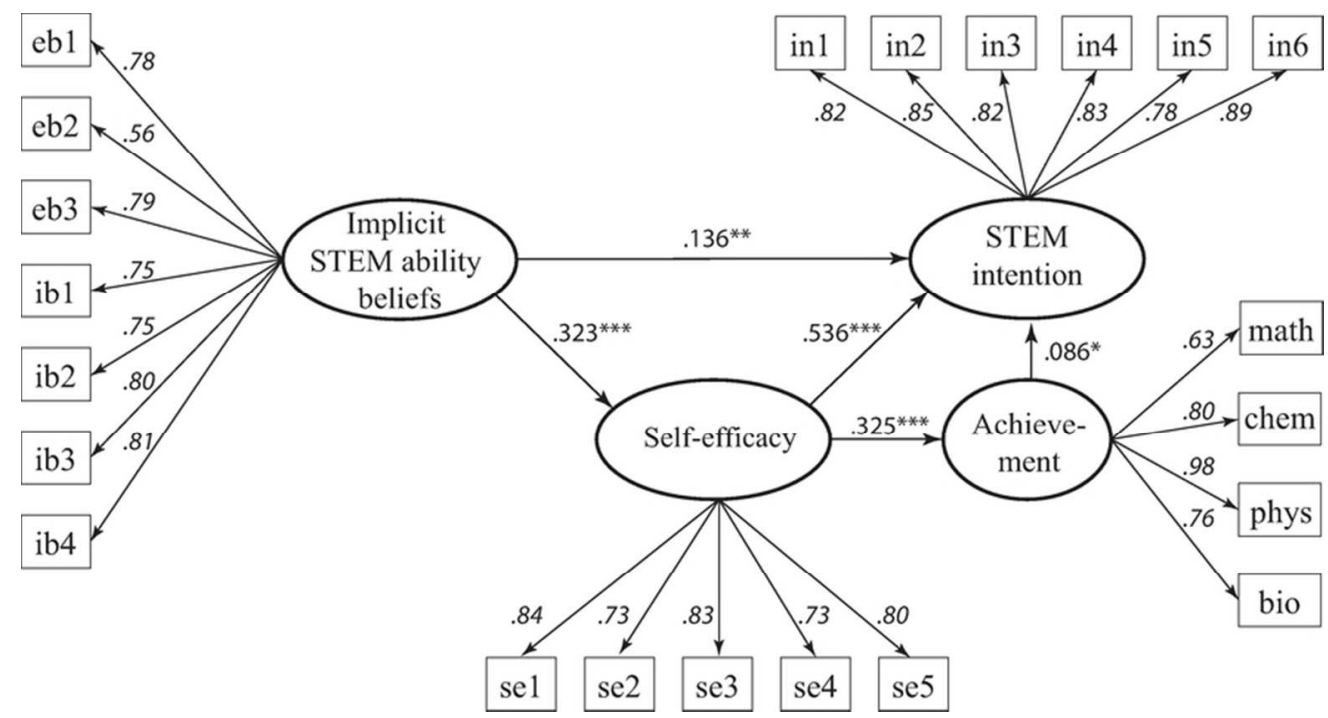

Figure 2. Structural mediation model of the influence of implicit beliefs about the malleability of STEM ability on STEM related self-efficacy beliefs and the intention to opt for a STEM bachelor's degree. Reported $\beta$ 's are the standardized estimates. Circles present latent variables and rectangles represent measured variables. All italic coefficient (factor loadings) were significant at $\mathrm{p} \leq .001$ level.

$* \mathrm{p}=.05, * * \mathrm{p}<.01, * * * \mathrm{p} \leq .001$.

$74 \times 40 \mathrm{~mm}(300 \times 300$ DPI $)$ 